Digital Media, Cycle of Contention, and Sustainability of Environmental Activism The case of anti-PX protests in China

Liu, Jun

Published in:

Mass Communication and Society

DOI:

$10.1080 / 15205436.2016 .1203954$

Publication date:

2016

Document version

Peer reviewed version

Citation for published version (APA):

Liu, J. (2016). Digital Media, Cycle of Contention, and Sustainability of Environmental Activism: The case of antiPX protests in China. Mass Communication and Society, 19(5), 604-625.

https://doi.org/10.1080/15205436.2016.1203954 
Forthcoming in Mass Communication and Society, 2016.

\title{
Digital Media, Cycle of Contention, and Sustainability of Environmental Activism - The case of anti-PX protests in China
}

\author{
Jun $\mathrm{Liu}^{\mathrm{a}, \mathrm{b}}$ \\ ${ }^{a}$ Department of Media, Cognition and Communication, \\ University of Copenhagen, \\ Karen Blixens Vej 4, 2300 Copenhagen S, Denmark \\ Phone: $+45-35328416$ \\ Email: liujun@hum.ku.dk \\ ${ }^{\mathrm{b}}$ Centre for Communication and Computing, \\ University of Copenhagen, \\ Karen Blixens Vej 4, 2300 Copenhagen S, Denmark
}

\begin{abstract}
Although scholars have studied issues arising from digital activism, most have failed to scrutinize the possible interconnections that might be found within digitally mediated political contention. To advance such an understanding, this study employs the concept of "cycles of contention" to investigate recurrent mechanisms of protest in contemporary society. This study takes as its case seven anti-petrochemical (anti-PX) protests in China from 2007 to 2014, during which 54 in-depth interviews are conducted. Whereas traditional media coverage legitimizes and modularizes anti-PX protests, facilitates the adoption of digital media as part of the repertoire of contention, and sustains political contention in a long run, the use of digital media enables protestors to diffuse contention widely and quickly, and allows them to learn from the experiences of the past. This study concludes that the sustainability of digitally mediated environmental activism is shaped by the specific communication ecology in China.
\end{abstract}

Keywords: digital media, political activism, cycles of contention, repertoire of contention, environmental activism, anti-PX protests, China 


\section{Authors' biographies}

Jun Liu is an assistant professor in the Department of Media, Cognition and Communication and the Centre for Communication and Computing at University of Copenhagen, Denmark. His research areas cover political communication, information and communication technologies, and political sociology. He has articles published in Mass Communication and Society, Television \& New Media, Social Movement Studies, and Modern Asian Studies, among others. His research has won several awards, including The Best Dissertation Award, The Information Technology and Politics Section of American Political Science Association (2014) and the Best Paper Award, the 2014 International Communication Association Mobile Preconference. 
“...Pollution: Xiamen residents do not want it! Kunming residents do not want it! Shifang residents do not want it!... We Maoming residents do not want it either!”

- Message A

"A PX project that has been forbidden in Xiamen and discarded by Dalian will be extended in Zhenhai, Ningbo...PX is paraxylene, which easily leads to cancer and pathological changes of the reproductive system; please forward this message if you live in Ningbo!"

- Message $B^{1}$

At the end of March 2014, a message (Message A) went viral through both the internet and mobile phones in China, including text messaging, online forums, the online instant messenger QQ, the Chinese microblogging platform weibo, and Wechat, a Whatsapp-style social networking app. Following the dispersion of the message, thousands of residents of Maoming in Guangdong Province took to the streets, holding signs protesting a proposed PX project. On-the-spot images and videos of protests, together with environmental and health concerns over the project, proliferated on the internet and mobile social networks, attracting widespread news coverage in both national and international media (e.g., BBC, 2014).

The anti-PX protest in Maoming is more than just one of the thousands of political contentions in contemporary China that has caught public attention and manifested the increasing adoption of information and communication technologies (ICTs) as means of protest. Instead, it is also the latest in - and a reminder of - a series of protests against PX projects in China between 2007 and 2014, following the activism in Xiamen (Xie \& Zhao, 2007), Kunming (Chang, 2013), and Shifang (FlorCruz, 2012), as the message exemplifies. Similar to the protest in Maoming, the wide and rapid diffusion of Message B via the internet and mobile phones launched a four-day protest with over 5,000 participants against a PX

\footnotetext{
${ }^{1}$ Paraxylene is a petrochemical feedstock used in plastics, polyester, and other synthetic manufacturing. Xiamen, Dalian, Ningbo, Kunming, and Maoming in the two messages are cities in China, and Zhenhai is a district of Ningbo.
} 
project in Ningbo, Zhejiang province, in 2012 (Liu \& Yan, 2012). Besides a call for further distribution, the message articulated that the protests recalled the ones in Xiamen and Dalian. In short, earlier anti-PX protests spawn subsequent ones, underpinning a movement continuity against the PX project in China.

How to explain these protests - especially how to explain the continuity between these digitally mediated anti-PX protests? Which factors lead to the continuity of the adoption of digital media for political activism here? A number of thorough studies have documented the increasingly prominent role of digital media in political activism in the processes of claimsmaking, network-bridging, information distribution, resource accumulation, repertoire diversification, and movement mobilization, to mention a few (e.g., Castells, 2012; Earl \& Kimport, 2011; van de Donk, Loader, Nixon, \& Rucht, 2004, for a review, see Garrett, 2006). Nevertheless, most of this scholarship tends to focus either on the analysis of discrete contentious events (e.g., McCaughey \& Ayers, 2013; van de Donk et al., 2004) or the comparative analysis of similar events (e.g., Bennett \& Segerberg, 2012; Castells, 2012). Such approaches fail to analyze the possible interconnections that might be found between different instances of (digitally mediated) political contention (e.g., the anti-PX protests above). ${ }^{2}$ To advance such an understanding, this study employs the concept of "cycles of contention" (Tarrow, 1993a, 1993b) to explore the recurrent mechanism of digital activism in contemporary society. It takes the recurrent anti-PX protests in six cities in China from 2007 to 2014 as the case to examine the factors that contribute to the emergence and sustainability of assimilative digitally mediated environmental activism. This study sheds light on the enduring mechanism of digital activism and political contention in authoritarian regimes like China.

In this study, I first present a critical review of current studies of ICTs and political

\footnotetext{
${ }^{2}$ Although recognizing the interconnection, or acts of imitation within different forms of activism, most of these studies did not probe very deeply into these interconnections or acts of imitation (e.g., Bennett \& Segerberg, 2012, p. 745-747).
} 
activism with a focus on digital activism in China. Second, I introduce and develop the concept of "cycles of contention" as the theoretical framework to scrutinize the factors that shape the mechanism of recurrence and that sustain digitally mediated political contention. Third, I specify case selection and overview, data collection, and methods of analysis. Fourth, I examine the mechanism that produces the recurrence of certain strategies of digitally mediated environmental activism and digital media as "repertoires of contention" (Tilly, 1986). I conclude with thoughts on the mechanism that underpins the dynamics of digitally mediated, sustained political activism beyond a single contentious event.

\section{Digital Media and Political Activism: The Case of China}

Scholars are increasingly discussing the ways in which digital media is being used in political activism around the world. Some explore the affordance of digital media for information distribution for political contention (e.g., Hands, 2011; Kahn \& Kellner, 2004). Others underline the relevance of digital media in the process of structuring and bridging networks for collective action (e.g., Bennett \& Segerberg, 2012; Biddix \& Park, 2008). Some argue for digital media being a catalyst for protest organization, mobilization, and participation (e.g., Liu, 2015; Rojas \& Puig-i-Abril, 2009). Others observe identity- and value-driven subpolitics as key elements in digitally mediated political activism (e.g., Bakardjieva, 2009; Yang, 2009).

The impact of digital media on political activism has also become an enduring and substantial focus in the studies of ICTs in China (e.g., Yang, 2009; Zheng, 2008; for a critical review, see Qiu \& Bu, 2013, p. 126). Nevertheless, the scholarship remains dominated by case studies of discrete, independent - in some cases, isolated - contentious events, the emergence of which reflects unique internal dynamics (e.g., Yang, 2009; Zheng, 2008). Although such an approach generates a fruitful understanding of the use of digital media for single, concrete 
contentious events, it fails to explore possible interconnections within digitally mediated political activism and, further, to recognize their long-term effects. This reflects, to a certain extent, a crucial characteristic of political activism in Chinese society where the politically sensitive authorities worked hard with a highly repressive policy against protests in order to suppress the outbreak of political contention and to prevent the dispersal of its influence to a large scale, in particular, via digital media (e.g., King, Pan, \& Roberts, 2013; also see Bamman, O'Connor, \& Smith, 2012; MacKinnon, 2009). In this sense, as some studies suggest, “...activism in China fails to meet the definition of a 'social movement' because it is usually localized and falls short of sustained contention” (Huang \& Sun, 2014, p. 87).

However, existing scholarship does observe and acknowledge that earlier political struggles affect, facilitate, or even legitimize subsequent contentious movements, consequently transgressing specific contentious events and generating a long-term influence in the society. For instance, several studies on digital media and political movements discover that early protests not only become the blueprint for later political movements, but also lend "legitimacy" to later struggles (Lee \& Ho, 2014, p. 34-35; Hu, 2012; Zeng, 2015). Yang reminds readers of the "gradual revolution" in China under the influence of online political activism by proposing that "these popular political forms have already left their imprints on Chinese politics....they add up and their cumulative effects are profound" (2011, p. 10441045). In this sense, failing to recognize the imprint of early-riser activism on latecomers and the interconnections between them leaves significant lacunae in our understanding of the sustained influence of political activism on Chinese society.

Meanwhile, social movement studies have long argued that contentious events are hardly discrete phenomena, independent of one another (McAdam, 1995, p. 218, also see Minkoff, 1997; Traugott, 1995). Instead, they not only share a "family resemblance" (McAdam, Tarrow, \& Tilly, 2001, p. 165), they also encourage the emergence of assimilation, further 
lowering constraint and forming opportunities for broader and recurring contention (e.g., Tarrow, 2010; 2011, p. 201; McAdam, 1995). To go beyond a single contentious event as the unit of analysis and instead canvass the interconnection dynamics of political activism, a feasible method might be to draw on the concept of "cycles of contention."

\section{Beyond the Single Contentious Event: Cycles of Contention}

Cycles of contention, modular collective action, and repertoires of contention

The concept of "cycles of contention" has been coined in the works of Tarrow (1993a, 1993b)

to enunciate the rolling, recurrent mechanism of protests and its contribution to longer-term changes in collective action and society at large (see also McAdam et al., 2001, p. 65-68; Traugott, 1995). According to Tarrow, a "cycle of contention" refers to

“...a phase of heightened conflict across the social system, with rapid diffusion of collective action from more mobilized to less mobilized sectors, a rapid pace of innovation in the forms of contention employed, the creation of new or transformed collective action frames, a combination of organized and unorganized participation, and sequences of intensified information flow and interaction between challengers and authorities." (2011, p. 199)

"Cycles of contention" acts as a key term to explicate the translation of forms of collective action in moments of contention into the historical development of means for making claims and engaging in struggles in a society, known as the "repertoire of contention."

As Tilly defines it, the "repertoire of contention" is "...a limited set of routines that are learned, shared, and acted out through a relatively deliberate process of choice" (1995, p. 42). The repertoire of contention is an array of contentious claims-making and performance that is always situated in prior societal experience. People learn from the history and experience of contention and then borrow or imitate these "learned conventions of contention" (Tarrow, 
2011, p. 29) in later struggles. Thereby, most of the time, the tactics or forms of collective action in any given place bear a strong resemblance to previous iterations. The consequent borrowing or imitation leads to cycles of certain types of protest in a society. In this cyclical process, a stock of these inherited tactics or forms of collective action that become habitual and that transfer across different contentious contexts consequently become "the permanent tools of a society's repertoires of contention" (Tarrow, 1993a, p. 284).

A key contribution from cycles of contention to what becomes the eventual repertoire of contention is the modularization of emerging forms of struggles, which facilitates the diffusion of these forms and ultimately leads to their translation into permanent changes in the repertoire of contention. To be clear, the outcome of recurrent struggles influences the shape of the next by providing an array of possible tactics and, more importantly, "modular repertoires" (Tarrow, 1993a; Tilly, 1986, p. 6). The modular repertoires manifest in the capacity of forms of collective action to be used in a variety of conflicts by a number of different social actors and by coalitions of people against a variety of opponents (Tarrow, 1993b, p. 77). As such, the modularity of collective action allows for the transferability of repertoires into different contexts (Wada, 2012). In short, cycles of contention entail models of collective action that allow the outcome of a single moment of political activism to transcend beyond itself as such and to sustain collective challenges for later-comers.

Cycles of contention also bring the possibility of institutional change by engendering an indirect effect on the political opportunity structure and constraints, as people challenging authority increase the leverage of other groups to challenge authorities and elevate their own power or privilege (McAdam, 1995, p. 221-222). In this sense, cycles generate a longer and broader influence of protest that goes beyond a concrete contentious event by diffusing, fashioning, and legitimizing forms of collective action. Accordingly, McAdam suggests that we "...shift our focus of attention from discrete social movements to the broader 'movement 
families' or 'cycles of protest' in which they are typically embedded" (1995, p. 218).

Organizations, mass media, and diffusion of contention

A key element to facilitate cycles of contention is the diffusion of contention, which allows “... word of successful - and learnable - collective actions" to be spread to more groups and localities for mimetic struggles and "...be sustained far longer than the episodic and cathartic collective actions of the past" (Tarrow, 1993b, p. 82). Some studies recognize the relevance of organizations (e.g., Social Movement Organizations [SMOs]) or associational networks in the process of distributing information in established networks as a precondition for diffusion (McAdam, 1995, p. 232; Minkoff, 1997). Others observe the significance of the media in the process of disseminating the news about protests beyond their immediate social settings (Oliver \& Myers, 1999, p. 39). Studies recount that mass media play a critical role in the progression of protest cycles by broadcasting action strategies to potential adopters, connecting otherwise unconnected individuals via a shared response to events, shaping the public opinion and framing of contention issues, and routinizing protests as institutionalized politics (for detailed discussions, see Gamson \& Wolfsfeld, 1993; Oliver \& Myers, 1999; Oliver \& Maney, 2000; Tarrow, 2011, p. 201).

Studies increasingly find out that digital media such as the internet facilitates the transfer of "protest ideas and tactics quickly and efficiently across national borders" (Norris, 2002, p. 208). Boyle \& Schmierbach (2009) dissect the emerging role of alternative media (i.e., the Web) in prompting both traditional and protest participation. Tufekci and Wilson (2012) discuss how sharing prior personal protest experiences via social media drove the follow-up protests in Egypt.

Nevertheless, current studies are largely based on protests in Western democracies, and they fail to consider the diffusion of - and thereby the cycles of - contention in highlycontrolled authoritarian regimes like China. The Chinese government works hard to impose a 
tightening of state control over both traditional and digital media. The diffusion of information on protests especially suffers from intensive suppression (e.g., King et al., 2013). Meanwhile, several studies demonstrate that social organizations, such as environmental NGOs, have been missing in the process of political activism, largely due to political pressure and surveillance (Wu \& Wen, 2015, p. 113). How can the diffusion and further cycles of contention develop in a highly controlled, politically sensitive context, in which both protest information and social organizations have been under strict governmental control? Such a context makes China a relevant case to understand the recurrent dynamics of political activism. The overarching research question becomes:

What specific factors and processes account for the recurrent dynamics of digital activism in a highly-controlled context such as China?

In effect, this single question is replaced by three separate queries:

1) How do people get information about protests - including information about political activism of the past and present?

2) What are the factors that contribute to people's perception of digital media as the repertoire of contention?

3) What are the processes - e.g., diffusion of knowledge about protests - by which earlier movements facilitate follow-up activism and further generate cycles of contention?

\section{Methods}

The study examines seven anti-PX protests in six cities from 2007 to 2014. Starting with the anti-PX protest in Xiamen in 2007, PX has become a common target for public protest and environmental activism in China. Since then, as a result of public discontent, anti-PX protests have broken out in several cities including, chronologically, Chengdu in 2008, Dalian in 
2011, Ningbo in 2012, Kunming and Chengdu in 2013, and Maoming in 2014. ${ }^{3}$ Among them, some cities are known for their peace and quiet, rarely witnessing protests (e.g., Xiamen and Kunming). The process also consists of varied social groups, including students, intellectuals, villagers, as well as journalists, police, professionals, and other types of urbanites (e.g., the middle class in Xiamen, Dalian, and Kunming). In short, the original anti-PX protest has grown into one of the most prominent, recurrent forms of environmental activism in contemporary China.

More importantly, the anti-PX protests have witnessed the adoption and appropriation of digital media as an indispensable means of political activism. As early as 2007, people largely relied on mobile communication to organize the anti-PX protest in Xiamen (Liu, 2013). In subsequent protests, people continued to exploit various digital media to galvanize protests, including internet forums, QQ, weibo, text messaging, and WeChat, where protestors shared information and protest plans as well as facilitated collective action mobilization (e.g., Sevastopulo, 2014). Photos, videos, and on-the-spot reports of the protests have also spread in real-time via, for instance, weibo, WeChat, Facebook, and Twitter. The anti-PX protests thus allow us to observe the integration of digital media into environmental activism and its possible contribution to the sustainability of environmental activism.

From these cases, I used snowball sampling and in-depth interviews with protest participants to explore both the diffusion of protests over the course of political activism and perception of digital media as a repertoire of contention. In China's tightly controlled and monitored political environment, the distribution of protest information is strictly prohibited, as is personal participation in the protest. The snowball sampling allowed the researcher to identify and recruit "hidden populations," or individuals or groups that are not easily

\footnotetext{
${ }^{3}$ Nevertheless, this does not mean that interconnection only exists between the anti-PX protests. Rather, people were inspired by the anti-PX protests and imitated them in other instances of political activism, see, for instance, Hu, 2012, p. 104.
} 
accessible through other sampling strategies (Salganik \& Heckathorn, 2004). To access the hidden populations of protestors in these cases, I identified three to five participants in six cities and then asked them to provide three to five persons they met during protests, from whom they received protest information, or to whom they delivered the information. This process aims to discover as many protest participants as possible. I replicated this process to identify and recruit the remainder until the process stopped of its own accord. This networkbased sampling procedure guaranteed the interviewees' privacy and ensured that their participation in protests would be kept to a low profile. Of the initial 85 participants contacted for the study, 54 agreed to be interviewed. The interviewees were an average age of 35.7 years old. Eighty-three percent of them (45 out of 54) had a bachelor's degree - or higher; but all were internet users who were familiar with digital media in various forms. The professions of the interviewees included journalist, editor, graduate student, high-school student, lawyer, sales representative, consultant, university lecturer, taxi driver, IT professional, mobile phone salesperson, barber, and small clothing storeowner. A total of 50 interviewees physically participated in the protests, while four participants attended the protests "virtually" - they were engaged in the distribution of protest information via online forums and social networking sites (e.g., Facebook and weibo). The interviewees all shared a firm understanding of ICTs as a relevant means of anti-PX protests. Such an understanding is relevant for the analysis of the perception of digital media as a repertoire of contention.

I conducted semi-structured in-depth interviews, following the direction and general framework of the interview while eliciting detailed responses and probing when clarification is necessary. In particular, I adhered to the notion that "...the repertoire is not only what people do...it is what they know how to do and what others expect them to do" (Tarrow, 1993b, p. 70, emphasis in original). Questions in the interview guide thereby included not only the use of digital media for protests, but also how the interviewees knew and perceived 
digital media as a means of struggle, what kind of experience or knowledge they had for the protests, where this experience or knowledge came from, and how it was gained, justified, and validated via which channel.

The interviews lasted 1.5 hours. Of the 54 interviews, I conducted 48 face-to-face by traveling to the cities where the interviewees resided and the remaining six via Gmail due to a concern about government surveillance of social media and e-mail communication. I conducted all interviews in Chinese and in person, which I then transcribed and translated. I only documented interviews when the interviewee was comfortable and anonymity could be guaranteed.

After data collection, I employed thematic analysis and cross-case synthesis (Yin, 2009, p. 18) to determine which factors contributed to and further sustained the diffusion and recurrence of environmental protests.

\section{Findings}

This section presents the findings from the interviews about the diffusion of contention and the perception of digital media as a means of contention. The interviews demonstrate that diffusion emerges from social and group-based applications of digital media and then spreads to other digital media platforms. Following that, traditional media such as newspapers and TV start to publish news about protests. Although both contribute to the diffusion of information about anti-PX protests - in particular, the use of digital media for political activism traditional and digital media accomplish this in different ways.

\section{Diffusion of contention via digital media}

In an atmosphere where both mass media and social organizations are under highly repressive control, digital media act as a crucial channel for people to distribute and receive information regarding 1) politically sensitive issues (e.g., PX), 2) collective action mobilization, 3) 
collective action of the past, which enables people to learn from earlier experiences.

According to the interviews, people categorized various digital media into two segments: one includes social and group-based applications of digital media, such as QQ, WeChat, and mobile phones; the other has digital media platforms such as weibo, web pages, and online forums. First, social and group-based applications of digital media served as the primary source of relevant but politically sensitive information - PX-related information in this case. In practice, 94 percent (51 of 54) of interviewees said that the information about the PX project emerged and circulated within their social networks via mobile call, text messaging, $\mathrm{QQ}$, and WeChat. The rest received the information via face-to-face interaction and also from their digitally mediated social networks. For instance, several participants in the Xiamen case recalled that around three months before the protest, they started to receive "a warning text message regarding the PX project" ${ }^{, 4}$ from their friends, colleagues, and relatives, which was the first time for them to hear the name "PX." The text message ran rampant within a short time, while, according to a 35-year-old taxi driver, "local media did not mention this issue at all for over three months." Against this backdrop, reportedly, the phrase "did you receive the [PX-related] SMS?" became the opening remark when Xiamen residents met each other during this three-month period (Zhu, 2007). In this sense, it is the information from mobile social networks that informed people and initiated further discussion about the project.

If Xiamen residents basically relied on text messaging to receive and spread PX information, later protests adopted various social network-based digital media for the same purpose. In the cases of Kunming, Chengdu, and Maoming, local residents mostly used QQ and WeChat to disseminate PX information, inform their social networks, and initiate discussions, even if traditional media did not cover the issue at all. In other words, people no longer had to depend on traditional media as a key information source.

\footnotetext{
${ }^{4}$ For the detailed information of the text message, see Xie \& Zhao, 2007.
} 
Second, in addition to the diffusion of PX-related information, people also spread mobilizing messages for "strolls (sanbu)," a euphemism they used for street protests, via social and group-based applications of digital media. In the Xiamen case, the mobilizing message had been disseminated largely via mobile communication. Similarly, as we have seen at the beginning of the article, the messages calling for protests proliferated via digital media and fundamentally turned into a key part of the mechanism of mobilization in the cases of Ningbo and Maoming.

Importantly, such information got immediate attention and action from people, as it came from their (digitally mediated) social networks. A 43-year-old IT engineer from the Maoming case explained:

“...it [the message] came from someone you know, you trust, and you care about...That means it [the message] is relevant; it is urgent. It is an appeal from your social network that asks for your immediate response."

This statement shows that the embedding of social relations into the process of digitally mediated mobilization exerts an essential influence on people's attitudes towards the message they received and triggers immediate, follow-up action: they were inspired to distribute the message widely in their digitally mediated social networks, and to search for further information about PX, for instance, via search engines and in weibo. These actions furthered the swift diffusion of protest information throughout society and inspired collective action.

More specifically, the ease-to-use feature of digital media allows people to invite their social networks into collective action mobilization without much effort. A 23-year-old graduate from the Kunming case said that she had forwarded the message via WeChat to her whole class and her relatives, a total of 75 people, by “...just twiddling the thumb." In the Xiamen case, the apex of the anti-PX movement occurred as "millions of Xiamen residents frenziedly forward[ed] the same [mobilizing] text message around their mobile phones" (Lan 
\& Zhang, 2007), urging each other to join a street protest opposing the government's PX project. The interviewees from other cases also confirmed that they had forwarded such mobilizing messages to different social groups they affiliated with by "copying," "pasting," and "sending" the message or simply pressing the "forward" or "retweet" button. The easy-touse digital devices with inexpensive telecommunication fees for information dissemination became the key facilitator - be it through text messaging, QQ, or WeChat - to mobilize as many people as possible into the protest.

Third, people moved to search engines, microblogging sites, and online forums to look for information about PX after receiving the message from their digitally mediated social networks. These digital platforms became major channels for them to explore more detailed information about the issues they were concerned with and, more importantly, to retrieve information about previous protests concerning these issues in order to learn from them. The interviewees reported that they found out a lot of information about anti-PX protests in other cities as soon as they searched keywords such as "PX" via digital media. Then they read and learned from these past experiences. A 33-year-old clothing storeowner from Ningbo described it thus:

“...You can find web pages, online forums, and tweets including photos and videos of the anti-PX protest in Xiamen, the very first one in 2007. These contents expand our awareness of the PX project...it shows to us the way we can adapt to stop the project."

While the protest in Xiamen remained "the most renowned anti-PX protest," according to a 27-year-old mobile phone salesperson from Chengdu, people can also easily retrieve news, photos, and videos about later ones in Kunming, Dalian, and so on from web pages, microblogging, blogs, and online forums despite censorship. She said,

“...after checking the internet, we saw several anti-PX protests around the nation. If the project is not toxic or problematic [as the government declared], why would people in 
other cities oppose it? Why do we need a project that people elsewhere discarded? If they [people in other cities] succeeded in forcing the government to give up the project by protests, we should also do the same!"

Although such "reasoning" did not convert into offline protest action directly, it did encourage people to re-distribute the information via digital media within their social networks. As soon as these messages had been spread via diverse digital platforms, they multiplied within a very short time and spread to services beyond the control of state censors. For one thing, the messages diffused through decentralized network infrastructure before the government recognized it and initiated censorship. For another, the rapid and widespread diffusion of these messages made it impossible for the government to eliminate them completely. In this way, information about the anti-PX protests proliferated within digitally mediated social networks, allowing as many people as possible to know and learn from these experiences.

To sum up, digital media, both the social and group-based ones and web pages, online forums, and microblogs became a crucial channel of the diffusion of protest information, which includes both mobilizing messages and the past experiences of protests. The social and group-based applications of digital media enable people to distribute information that demands immediate attention and action as quickly and as widely as possible. Meanwhile, web pages, online forums, and microblogs provided abundant information, especially about previous protests. Such information greatly shaped people's perception about the PX project and laid the foundation for further contention.

\section{Coverage and diffusion of contention via traditional media}

People also read the information about the PX project, the ensuing debate, and the coverage of anti-PX protests in traditional media. According to the interviews, traditional media refers to the state-controlled media, such as newspapers and TV. In general, the information from 
traditional media tries to persuade the public to accept the PX project by citing professional opinions or by claiming that ill-intended protesters falsified or exaggerated the toxicity of PX to mislead the public. Interestingly, the information from traditional media failed to change attitudes toward the project. Instead, it enriched knowledge of the protests, provided successful, learnable examples to follow, and acted as a deterministic element to encourage adoption of digital media for protests.

First, traditional media's coverage of the controversies and objections against the PX project services acted as a catalyst to ignite widespread contention against the project, as people perceived the emergence of the coverage as both the removal of censorship and an admission of the danger of the PX project by the authorities. In practice, traditional media's coverage of PX-related information did not turn up until the information proliferated within social and group-based digital media. For instance, local media in Xiamen started to cover the PX project only after the controversies spread via mobile phones for around three months. Meanwhile, the authorities worked hard from the beginning to censor sensitive words such as "PX" and "petrochemical," shutting down online forums that contained arguments against the project and blocking access to overseas coverage of this issue. Nevertheless, facing the proliferation of PX-related information via digital media and the coverage by international media, traditional media also started to cover the debate. This significant change was perceived as the cessation of censorship regarding the debate over PX. The interviews showed that people believed that, following the traditional media coverage, they were allowed to argue against the PX project publicly. A 38-year-old IT professional said, “...even the government had to admit the detriment of the PX project in [mass] media! Why can't we oppose it?"

Second, the traditional media coverage on the anti-PX protest encouraged people to learn and imitate earlier collective actions - in particular, the successful "stroll" in Xiamen - 
against the project. According to the interviews, official media, such as People's Daily, the official newspaper of the Communist Party of China, China Newsweek, published by China News Service, the second-largest state news agency, and national and regional level newspapers such as Southern Metropolis Daily, covered the anti-PX protests. To them, the coverage implied that “...the (central) government had accepted 'the stroll,' or street protest, as a legit way of opposing the PX project" (A 36-year-old taxi driver from the Chengdu case). As an authorized symbol (O'Brien, 1996, p. 37) from the central government, the coverage became not only a benchmark of anti-PX protest, but also a successful, politically accepted example for people elsewhere to learn, follow, and duplicate later. For instance, a 42-year-old university lecturer from the Kunming case explained,

"...the media will not be allowed to cover the protest in Xiamen if it is an illegal act. Now it [the protest] appears in the news, which means the government recognized this activity as a legitimate form of public participation in the PX issue...we can take to the streets as people in Xiamen did [to march against the PX project]."

Third, traditional media's coverage plays a key role to influence the adoption of digital media for protests. The way these media covered anti-PX protests underlined the relevant role of digital media in initiating and organizing protests, serving as examples for people to learn from the past by adopting and appropriating various digital media for protests. For instance, the interviewees from several cases mentioned a report by China Newsweek. Titled "The Power of Mobile Messaging" (Xie \& Zhao, 2007), the report detailed how Xiamen residents used text messaging to organize the anti-PX protest. People treated this report as a signal from the authorities giving tacit consent to using mobile phones for successful protest organization. A 36-year-old accountant from the Chengdu case recalled,

“...even the central authorities acknowledged the power of mobile phones for successful protest. We can copy the 'stroll' in Xiamen by using our mobile phones to organize 
similar protests against the PX project. This successful example shows a way recognized by the government to oppose the project."

Similarly, in later coverage on the anti-PX protests, traditional media reported the use of various digital media as a means of protest, which consequently becomes the main driving force that inspires and encourages the "replication" of successful examples of the past by employing digital media for protest.

To sum up, traditional media played a key role in shaping knowledge of past protests, which facilitated digitally mediated protests against the PX project. Although none of these reports said that the protests were legal, media coverage was considered to be a withdrawal of censorship over opposition against PX, the go-ahead signal for protest activity. Similarly, the way these reports covered the anti-PX protest played a fundamental role in shaping attitudes and actions against the project. The coverage of the use of digital media was perceived as an encouragement to follow "the successful model" of the past by adopting digital media for political contention, which has accordingly sustained the digitally mediated anti-PX protests.

\section{Discussion}

In a series of recurring protests against PX projects from 2007 to 2014, this study observes that both digital and traditional media facilitate the diffusion of contention and contribute to the mechanism of recurrence, but in two distinct ways. The affordances of digital media, such as ease-of-use, immediacy, and the embedding of social networks, generate a process of mass self-mobilization, through which people not only disseminate protest information as quickly and widely as possible, but, more importantly, it allows them to rapidly engage in collective action mobilization. In this process, the rapid and wide dissemination by virtue of digital media allows the past experience of collective action to be available and accessible to the public to learn, duplicate, and adopt in practice despite censorship. Further, the coverage of 
contention by traditional, official media not only legitimizes but also modularizes the contention, further encouraging the emergence of assimilation. More importantly, traditional media plays a crucial role in shaping perception of digital media as a repertoire of contention, which leads to the sustainability of digitally mediated political contention. This section explores the different contributions of digital and traditional media in terms of the diffusion, legitimation, and modularity of contention respectively, followed by a discussion of digital media as a repertoire of contention and the sustainability of anti-PX protests as an example of environmental activism in contemporary China.

\section{Digital media, diffusion of contention, and mass self-mobilization}

Due to the fear of the contagion effect of protests, the Chinese government struggles hard to detect and eradicate collective action information as it emerges. Against this backdrop, digital media serves as a key resource of the diffusion of contention against censorship. More specifically, the unique affordances of digital media, including availability, accessibility, and affordability, facilitate the proliferation of information without the engagement of traditional media and generate a process of what I call "mass self-mobilization."

First, availability indicates that low-end ICTs have become a simple yet substantial necessity for everyday life, which institutes the adoption of digital media as a quotidian tool for political activism. In China, the population of mobile phone users surpassed 1.2 billion, or 94 percent of its total population, in 2014. The mobile messaging app WeChat has over 500 million active users monthly. Over 290 million weibo users account for $45.9 \%$ of the total 632 million Chinese internet users in 2014 (CNNIC, 2014). Due to the lack of institutional support and resources for political contention under authoritarian control, people appropriate and largely rely on their digital media, a mundane communication tool, to initiate and facilitate collective action (e.g., Huang \& Sun, 2014; Yang, 2009). Similarly, cases examined here show that the Chinese public takes advantage of digital media as the most readily available resource 
for protest distribution, organization, and mobilization.

Second, ease-of-use and low cost contribute to the accessibility and affordability of digital media - in particular, social and group-based applications of digital media - which allows instant dissemination of protest information and collective action mobilization to occur and renders digital media into a key resource for both informing and uniting individuals, even those who have little technological know-how. As the interviews exemplify, digital media allow people to spread politically sensitive messages, initiate collective action, or resist authority through a simple method - for instance, "twiddling their thumbs" on a mobile phone - to promote political activism. Meanwhile, with instant communication, digital media enables the release of contentious information at the flick of a button, be it through mobile phones or personal computers. In this way, the diffusion of contention, including past experience of struggles, easily transcends geographic boundaries and facilitates large-scale impact, for instance, international news coverage, leaving the government unable to cover up either the contested issue (i.e., the PX project) or the politically sensitive one (e.g., protest). Such diffusion is so relevant that it enables people, in varying degrees, to draw their impetus and inspiration from the collective action of the past.

Moreover, digital media delivers calls to act on the basis of social networks; in other words, it incorporates social relationship as the mobilization agent, which, in turn becomes the driving force for engaging in both information dissemination and collective action mobilization. In this process, as we have observed elsewhere (e.g., Bennett \& Segerberg, 2012; Liu, 2015), the digital technology affordances activate and articulate social networks for political contention. With help from digital media, the threshold for initiating, engaging, promoting, or supporting political action becomes low.

These affordances contribute to a process of "mass self-mobilization," which is inspired by Castells' phrase "mass self-communication" (2009, p. 55). In particular, the concept 
underlines a quasi-mass communication process on the basis of horizontal networks of digitally mediated interactive communication without mass media and organizational foundation. In the case of anti-PX protests, digital media first enable people to initiate a communication process through which they distribute protest information and mobilizing messages without an organizational basis. Next, digital media promote the practice of collective action mobilization. The term "self-mobilization" thereby goes one step further than self-communication by addressing the organizational process through which individuals, largely depending on their digital media, choose and mobilize by themselves those within their social networks. This process occurs when many circulate mobilizing messages spontaneously within their social networks. Consequently, digital media drives mass mobilization through interpersonal interactive practices in collective actions even without social organizations, transforming a means of interpersonal interaction into a mass-mobilizing tool. This point is relevant to understanding the digitally mediated process of collective action organization in the absence of social organizations, including SMOs, in authoritarian regimes.

\section{Traditional media and the legitimation and modularity of contention}

In a repressive political environment such as China, political contention normally faces great political risk and encounters harsh political suppression by the state (e.g., O'Brien, 2009). Against this backdrop, the mere diffusion of contention - or, for people, simply knowing about the protest - is not enough to inspire political activism. Instead, people exploit official ideologies through, for instance, “...the innovative use of laws, policies, and other officially promoted values" (O'Brien, 1996, p. 32) to legitimate their resistance and protest (also see O'Brien \& $\mathrm{Li}, 2006)$. In the case of the anti-PX protests, while digital media facilitate the diffusion and mobilization of contention, it is the traditional official media that legitimize and modularize the contention, further encouraging the emergence of assimilation in the long run.

First, traditional media's coverage increases the influence of the anti-PX protests by 
legitimizing the protest as a kind of "partially sanctioned resistance" (O’Brien, 1996, p. 33) and consequently encouraging widespread duplication. O'Brien noted in the study of rural contention that increased media penetration cultivated villagers to be "more knowledgeable about resistance routines devised elsewhere" (1996, p. 41). In the case of anti-PX protests, the government exerted censorship over PX-related information at the beginning, then later removed the censorship and allowed traditional media to cover the issue, including the protest. To the average person, the coverage of anti-PX protests implies that the controversies around the PX project were no longer a political taboo as soon as traditional media began to cover them. Instead, the authorities recognized its existence, allowing people to openly discuss, and, more importantly, accept the protest as legitimate. In other words, as the interviews show, the anti-PX protests have been recognized as "a form of officially legitimate public action" (Thireau \& Linshan, 2003, p. 87) in the general public (see Oliver and Myers, 1999, p. 44-45). The coverage by national mass media (e.g., China Newsweek), beyond the control of local authorities but considered as "an extension of state power" (Shi \& Cai, 2006, p. 329), significantly persuaded locals that their protest against local authorities' decision on the PX project had been tolerated and accepted with the connivance of the central authority, thereby establishing opportunities for later contention. This "schemata of interpretations" (Zhao, 2010, p. 42) perceived and shared by the public as a significant institutional policy change regarding the PX project consequently expand political opportunities for contention and encourage the adoption of such a form of collective action against PX projects for successors elsewhere.

It is also necessary to address the anti-PX protests as a specific form of environmental activism in contemporary China. By addressing its specificity, I mean the protest - and environmental activism in general - is tolerated by the authorities because it largely concerns environmental issues and does not challenge the authoritarian role (also see Zhao, 2010, p. 
45). As Yang and Calhoun emphasize, the emergence of "a green public sphere of critical environmental discourse" with a growth of environmental NGOs and a diversity of localized environmental movements in response to the rise of the environmental crisis since the early 1990s is distinctive, because "it engages politics and public policy without being primarily political.” (2007, p. 212; also see Sullivan \& Xie, 2009; Yang, 2005) This fundamentally lowers the political risk of the protest itself as well as that of the media to cover the protest.

Second, traditional media detail and highlight the use of digital media for protests, which leads to the modularity of anti-PX activism and further encourages imitation by late-comers. For instance, the interviewees recalled clearly that China Newsweek dedicated its cover story to the use of text messaging in the anti-PX protest in Xiamen. The reports described in detail how people appropriated their mobile phones to distribute "millions of messages" for protest mobilization (Xie \& Zhao, 2007). Similarly, later reports included the way in which people employed various digital media, such as QQ, online forums, and WeChat, to organize protests successfully (The Center for Public Opinion Monitor, 2014; Zeng, 2015, p. 112-113). In this way, traditional media covered the anti-PX protests and addressed the adoption of digital media as a unique and successful aspect of the protest. As news about this form of digitally mediated collective action spread, it generates a demonstration effect of the anti-PX protest by offering key tactics as "mobilizing information" (Lemert, 1984, p. 244). According to the interviews, the anti-PX protest has become a typical, successful model that crystallizes and acclaims digital activism in the process of struggling against authority and finally forcing it to change its decision. In this way, news coverage consequently modularizes the digitally mediated anti-PX protest as a successful example of protest organization and an established pattern of political engagement. The modularity of anti-PX protests accordingly establishes and facilitates patterns of digitally mediated contentious behaviors that "...can be learned, adapted, routinized, and diffused from one group, one locale, or one moment to another." 
(Traugott, 1995, p. 7) The tactical and organizational means and strategies that earlier anti-PX protests employed further afford later struggles. Thus, the coverage and diffusion by traditional media allows people to adopt modes of contention easily by learning from the past and duplicating it, facilitating its transferability into other cases, and furthering the popular perception of digital media as a repertoire of contention in society.

\section{Digital media as a repertoire of contention and the sustainability of anti-PX protests}

The contention repertoire involves specifically what people know how to do in contention (Tarrow, 2011, p. 39). Here, repertoire derives from the learned experience of the contested means of the past. In a series of anti-PX protests, a key contribution from traditional media to the recurrent mechanism of anti-PX protests is the establishment of the perception of digital media as a repertoire of contention. More specifically, it is the emphasis on digital media, be it text messaging or WeChat, in traditional media that leaves an impression binding anti-PX protests and the adoption of digital media together. As the interviews show, the coverage of protests by traditional media establish a framework in which digital media as a flexible and well-understood means of making claims and opposing others becomes a key option of these repertoires of contention. As people read the news coverage of anti-PX protests, this coverage becomes the "guideline" for people to duplicate the previous protest by adopting digital media as a means of engaging and spreading political contention. To the public, "the power of mobile messaging" not only depicts the political influence of mobile technologies, but also serves as a slogan to encourage people to adopt their digital media for protests. In this way, traditional media plays a key role in giving impetus to the knowledge of digital media as a repertoire of contention and, more importantly, the recurrent mechanism of digital activism.

\section{Conclusion}

Different from most current studies on political activism whose focuses remain on a singular 
contentious event, this study underlines the interconnections between instances of contention by employing the concept "cycles of contention" to investigate the recurrent mechanism of anti-PX protests in contemporary China. I argue that digital media plays a key role in informing people about the contention. But it is the traditional media that legitimizes and modularizes contention and encourages the emergence of repeated patterns of collective action. In this sense, the intertwining of digital media and traditional media generates the recurrent dynamics of contention and sustains the long-term influence of digitally mediated environmental activism in China.

This study advances the understanding of (digitally) mediated political activism in the following three perspectives: First, it depicts a nuanced picture about the distinct contributions from digital media and traditional media to the recurrent mechanism of contention. As this study argues, for the sustainability of political activism in authoritarian regimes such as China, it is not enough to have digital media or traditional media alone. Various types of media contribute to different elements of the recurrent mechanism.

Second, this study emphasizes the legitimation and modularity of contention as a key contribution from traditional media where repressive political policies discourage the emergence of contention. The prominence and success of political activism in official media do, in fact, promote learnable forms of struggle, expand political opportunities, and sustain political contention in a politically repressive context. This study resonates with Tarrow's argument that "...it was in the shadow of the national state that social movements developed their characteristic modular forms of collective action" (1993b, p. 85).

This study, by integrating the concept of "cycles of contention" into studies of political activism, proposes that a better understanding of contentious events emerges from the investigation of the historicity of the contention. As this study demonstrates, the historicity of political activism articulates the legacies of the past as the very conditions that constitute the 
present of political activism.

\section{Acknowledgements}

The author appreciates the comments from Klaus Bruhn Jensen, Ran Wei, and two anonymous reviewers.

\section{Funding}

This work was supported by the Carlsberg Foundation [grant number CF14-0385]; S. C. Van Fonden [reference number 1503].

\section{References}

Bakardjieva, M. (2009). Subactivism. The Information Society, 25(2), 91-104.

Bamman, D., O'Connor, B., \& Smith, N. (2012). Censorship and deletion practices in Chinese social media. First Monday, 17(3).

BBC. (2014, April 2). China Maoming environmental protest violence condemned. Retrieved from http://www.bbc.com/news/world-asia-china-26849814

Bennett, W. L., \& Segerberg, A. (2012). The logic of connective action. Information, Communication \& Society, 15(5), 739-768.

Biddix, J. P., \& Park, H. W. (2008). Online networks of student protest. New Media \& Society, 10(6), 871-891.

Boyle, M. P., \& Schmierbach, M. (2009). Media use and protest. Communication Quarterly, $57(1), 1-17$.

Castells, M. (2009). Communication power. Oxford: Oxford University Press.

Castells, M. (2012). Networks of outrage and hope. Cambridge: Polity.

Chang, M. (2013, May 17). Thousands protest Kunming PX plan. Global Times. Retrieved from http://www.globaltimes.cn/content/782252.shtml 
CNNIC. (2014, July). The 34th statistics report on internet development in China (July 2014). Retrieved from http://www1.cnnic.cn/IDR/ReportDownloads/201411/P020141102574314897888.pdf Earl, J., \& Kimport, K. (2011). Digitally enabled social change. Cambridge: The MIT Press. FlorCruz, J. A. (2012, July 6). People power a sign of times in China's internet age. Retrieved from http://edition.cnn.com/2012/07/06/world/asia/china-shifang-protest$\underline{\text { florcruzl }}$

Gamson, W. A., \& Wolfsfeld, G. (1993). Movements and media as interacting systems. The Annals of the American Academy of Political and Social Science, 528, 114-125.

Garrett, R. K. (2006). Protest in an information society. Information, Communication and Society, 9(2), 202-224.

Hands, J. (2011). @ is for Activism. London: Pluto Press.

Hu, Y. (2012). The internet and social mobilization in China. In F. L. Lee, L. Leung, J. L. Qiu, \& D. S. Chu (Eds.), Frontiers in new media research (pp. 93-114). London: Routledge.

Huang, R., \& Sun, X. (2014). Weibo network, information diffusion and implications for collective action in China. Information, Communication \& Society, 17(1), 86-104.

Kahn, R., \& Kellner, D. (2004). New media and internet activism. New Media \& Society, $6(1), 87-95$.

King, G., Pan, J., \& Roberts, M. E. (2013). How censorship in China allows government criticism but silences collective expression. American Political Science Review, 107(2), 1-18.

Lan, Y., \& Zhang, Y. (2007, May 29). Millions of Xiamen residents spread crazily the same SMS to against high-pollution project. Southern Metropolis Daily. Retrieved from http://news.hsw.cn/2007-05/29/content_6311487.htm

Lee, K., \& Ho, M.-s. (2014). The Maoming anti-PX protest of 2014. China Perspectives, (3), 33-39.

Lemert, J. B. (1984). News context and the elimination of mobilizing information. Journalism 
Quarterly, 61(2), 243.

Liu, D., \& Yan, S. (2012, October 29). Ningbo backs down from PX project. Global Times.

Retrieved from http://www.globaltimes.cn/content/740943.shtml

Liu, J. (2013). Mobile communication, popular protests and citizenship in China. Modern Asian Studies, 47(3), 995-1018.

Liu, J. (2015). Communicating beyond information. Television \& New Media, 16(6), 503-520.

MacKinnon, R. (2009). China’s Censorship 2.0. First Monday, 14(2).

McAdam, D. (1995). "Initiator" and" Spin-off" movements. In M. Traugott (Ed.), Repertoires and cycles of collective action (pp. 217-239). Durham: Duke University Press.

McAdam, D., Tarrow, S. G., \& Tilly, C. (2001). Dynamics of contention. Cambridge: Cambridge University Press.

McCaughey, M., \& Ayers, M. D. (2013). Cyberactivism. London: Routledge.

Minkoff, D. C. (1997). The sequencing of social movements. American Sociological Review, 62(5), 779-799.

Norris, P. (2002). Democratic phoenix. Cambridge: Cambridge University Press.

O'Brien, K. J. (1996). Rightful resistance. World Politics, 49(01), 31-55.

O'Brien, K. J. (2009). Popular protest in China. Cambridge: Harvard University Press.

O'Brien, K. J., \& Li, L. (2006). Rightful resistance in rural China. New York: Cambridge University Press.

Oliver, P. E., \& Maney, G. M. (2000). Political processes and local newspaper coverage of protest events. American Journal of Sociology, 106(2), 463-505.

Oliver, P. E., \& Myers, D. J. (1999). How events enter the public sphere. American Journal of Sociology, 105(1), 38-87.

Qiu, J. L., \& Bu, W. (2013). China ICT studies. China Review, 13(2), 123-152.

Rojas, H., \& Puig-i-Abril, E. (2009). Mobilizers mobilized. Journal of Computer-Mediated Communication, 14(4), 902-927.

Salganik, M. J., \& Heckathorn, D. D. (2004). Sampling and estimation in hidden populations using Respondent-Driven Sampling. Sociological Methodology, 34(1), 193-239. 
Sevastopulo, D. (2014, April 1). China PX plant protests spread to provincial capital Guangzhou. Financial Time. Retrieved from http://www.ft.com/intl/cms/s/0/cf6594fab98d-11e3-957a-00144feabdc0.html - axzz3ZeGWgZ3k

Sullivan, J., \& Xie, L. (2009). Environmental activism, social networks and the internet. The China Quarterly, 198, 422-432.

Tarrow, S. (1993a). Cycles of collective action. Social Science History, 17(2), 281-307.

Tarrow, S. (1993b). Modular collective action and the rise of the social movement. Politics \& Society, 21(1), 69-90.

Tarrow, S. (2010). Dynamics of diffusion. In R. K. Givan, K. M. Roberts, \& S. A. Soule (Eds.), The diffusion of social movements (pp. 204-219). Cambridge: Cambridge University Press.

Tarrow, S. G. (2011). Power in movement (3rd ed.). New York: Cambridge University Press.

The Center for Public Opinion Monitor. (2014). To guide the public opinion toward PX project in the Maoming protest. Public Opinion on Politics and Law, 114(14), 3-8.

Thireau, I., \& Linshan, H. (2003). The moral universe of aggrieved Chinese workers. The China Journal, 50, 83-103.

Tilly, C. (1986). The contentious French. Cambridge: Harvard University Press.

Tilly, C. (1995). Popular contention in Great Britain, 1758-1834. Cambridge: Harvard University Press.

Traugott, M. (1995). Repertoires and cycles of collective action. Durham: Duke University Press.

Tufekci, Z., \& Wilson, C. (2012). Social media and the decision to participate in political protest. Journal of Communication, 62(2), 363-379.

van de Donk, W., Loader, B. D., Nixon, P. G., \& Rucht, D. (Eds.). (2004). Cyberprotest. London: Routledge.

Wada, T. (2012). Modularity and transferability of repertoires of contention. Social Problems, 59(4), 544-571.

Wu, F., \& Wen, B. (2015). Nongovernmental organizations and environmental protests. In P. 
G. Harris \& G. Lang (Eds.), Routledge handbook of environment and society in Asia (pp. 105-119). London: Routledge.

Xie, L., \& Zhao, L. (2007). The power of mobile messaging. China Newsweek, 326(20), 16-17.

Yang, G. (2005). Environmental NGOs and institutional dynamics in China. The China Quarterly, 181, 46-66.

Yang, G. (2009). The power of the Internet in China. New York: Columbia University Press.

Yang, G. (2011). Technology and its contents. The Journal of Asian Studies, 70(4), 10431050.

Yang, G., \& Calhoun, C. (2007). Media, civil society, and the rise of a green public sphere in China. China Information, 21(2), 211-236.

Yin, R. (2009). Case study research (4th ed). London: Sage.

Zhao, D. (2010). Theorizing the role of culture in social movements. Social Movement Studies, 9(1), 33-50.

Zheng, Y. (2008). Technological empowerment. Stanford: Stanford University Press.

Zhu, H. (2007, May 30). Xiamen calls an abrupt halt to the PX project to deal with the public crisis. Southern Weekend, p. A1. 